\title{
STUDY OF AIR MOVEMENT AND TEMPERATURE DISTRIBUTION IN A GREENHOUSE USED AS A DRYER
}

\author{
Soumaïla TIGAMPO, Vincent SAMBOU, Younouss DIEYE, Pape Moussa TOURE, Séckou BODIAN
}

Laboratoire d'Energétique Appliquée (LEA), Ecole Supérieure Polytechnique (ESP), Université Cheikh Anta Diop

\begin{abstract}
Sun drying is the oldest way to preserve but also to valorize and store surplus agricultural production. Nowadays, several types of dryers have been developed, but the solar greenhouse dryer is an ideal solution in our tropical countries because of its implicit and higher load capacity. The greenhouse climate depends on several factors, namely the outdoor climatic conditions (air temperature, wind speed, radiation, etc.) but also on the type of materials used to cover the greenhouse. The study was carried out on a parabolic greenhouse covered by a polyethylene film with a concrete base (absorber) which in turn is placed on the ground and will be tested under the climatic conditions of Dakar, Senegal. It is in this context of sustainable development that this work is carried out. The goal is to determine the distribution of temperatures and wind speeds in the greenhouse. The simulation was carried out using the threedimensional computer fluid dynamics software (CFD). The turbulence method (k-E) was used and to solve the radiation transfer equation (RTE) we introduce the discrete ordered method DO. We also add the "Solar Load Model" which gives the position of the sun and its radiations in relation to the layout of the greenhouse according to the date and time of the simulation. The simulation is carried out in a closed greenhouse and the results found can be used to improve the design and control of the greenhouse climate. Air temperatures and velocities simulation give an average of $325.95 \mathrm{~K}$ and $0.114 \mathrm{~m} / \mathrm{s}$ respectively.
\end{abstract}

\section{Nomenclature}

PE: Polyethylene

Scat coef: Scattering coefficient

$\mathrm{n}$ : Refractive index

$\varepsilon$ : the emissivity

$\rho:$ density (kgm-3)

$\alpha$ : the absorptivity coefficient

Cp: specific heat (Jkg-1K-1)

$\lambda$ : thermal conductivity (Wm-1K-1)

DO: discrete ordered

$\Phi$ : transport variable

$\Gamma$ : is the diffusion coefficient

he: the heat transfer coefficient (Wm-2K-1)

$\mathrm{S} \phi$ : is the source term

RH: relative humidity

$\vec{r}$.

$\vec{s}$ is direction vector

$\vec{s}$

is scattering direction vector

$\mathrm{S}$ : stroke length (m)

$\sigma:$ is the Stefan-Boltzmann constant $\left(5,669.10^{-8} \mathrm{~W} \mathrm{~m}^{-2}{ }^{\circ} \mathrm{C}^{-4}\right)$

\section{Introduction}

Among the applications of solar technology we can mention solar dryer, which is useful for the development of our tropical countries, because the sun is an abundant source of energy for our continent. From outdoor drying to today, several types of dryers have been developed that use fossil fuels (electricity, fuel). The use of these types of dryer has an environmental problem caused by greenhouse gas emissions [1]. This is why it is necessary to use ecological systems from non-polluting green energy sources. Among these ecological systems, we note the importance of greenhouse dryers, which is an appropriate and environmentally friendly technique that uses only solar energy. In addition, it is easy to install and has a higher load capacity. The greenhouse climate depends on many factors such as the climatic conditions (temperature, wind speed and solar radiation) and the covering material [2]. The greenhouse can be used all year long for producers [3]. Therefore, a good understanding of the greenhouse's thermal behavior is important for the effective use of greenhouse climate control strategies. To make greenhouse dryers more efficient, several researchers have conducted studies to reduce heat losses from small greenhouses to large scale $[4,5,6]$. As in the drying process, air movement and heat transfers are related to air velocity. It is in this alternative that Computer Fluid Dynamics simulation (CFD) can be important in terms of air flow study, analysis and temperature distribution in a greenhouse. It is used to predict air speed, determine the distribution of temperature fields, increase work performance and efficiency. For this reason, several researchers have conducted CFD studies on the greenhouse. Most of the studies focused on the configuration of openings, this highlights the effect of the configuration of natural ventilation in a greenhouse. The CFD model here studies different configurations on the natural ventilation system. Natural ventilation affects the exchange of mass and heat between the inside of the greenhouse and its environment [7]. Studies on the numerical prediction of

\footnotetext{
* Corresponding author: tigamposoumaila@gmail.com
} 
the effect of opening arrangements on ventilation and energy transfer in a greenhouse. These transfers can be evaluated using fluid dynamics techniques. However, it combines the simultaneous resolution of the radiative transfer equations (RTE) and the convective equations in order to have an overview of the resulting climate in the greenhouse [8]. There are also night-time condensation studies for the design of moisture control strategies for unheated greenhouses [9]. Studies to optimize the ventilation of a solar greenhouse with a movable rear wall based on CFD calculations. The purpose of this study was to simulate the model environment and validate the outputs by comparison with measured data and finally to optimize the size of the rear wall openings based on CFD simulations. The results show that a $1.4 \mathrm{~m}$ rear wall opening increases the ventilation efficiency in a solar greenhouse with movable rear walls [10]. A fluid dynamic analysis (CFD) was digitally predicted from outdoor climatic conditions to analyze the temperature distribution within a Chinese solar greenhouse as a function of time. The study compared simulated air and ground temperatures with those measured. This results in an average temperature difference between the simulated and less measured values at night of $1.0{ }^{\circ} \mathrm{C}$ and $1.5{ }^{\circ} \mathrm{C}$ on a cloudy day [11]. On the same realistic approach of the CFD simulation which takes into account both the heat exchange between the ground and the low floor, the low floor and the inside of the greenhouse, the greenhouse and the outside environment. This work uses the same approach and the aim is to determine the distribution of temperatures and wind speeds in the greenhouse

\section{Materials and methods}

\subsection{Description of the greenhouse}

The simulation was carried out in a solar greenhouse installed at the Ecole Supérieure Polytechnique of Cheikh Anta Diop University in Dakar (latitude 14²73', Longitude $\left.-17^{\circ} 5^{\prime}\right)$. It has a parabolic shape with the following dimensions: a width of $6.60 \mathrm{~m}$, a length of $13.90 \mathrm{~m}$ and a height of $3 \mathrm{~m}$. The greenhouse is covered by polyethylene film of thickness $0.0002 \mathrm{~m}$ and has been equipped with two openings in front next to the entrance door and the concrete base is placed on the ground. The schematic view of the greenhouse is shown in Figure 1.

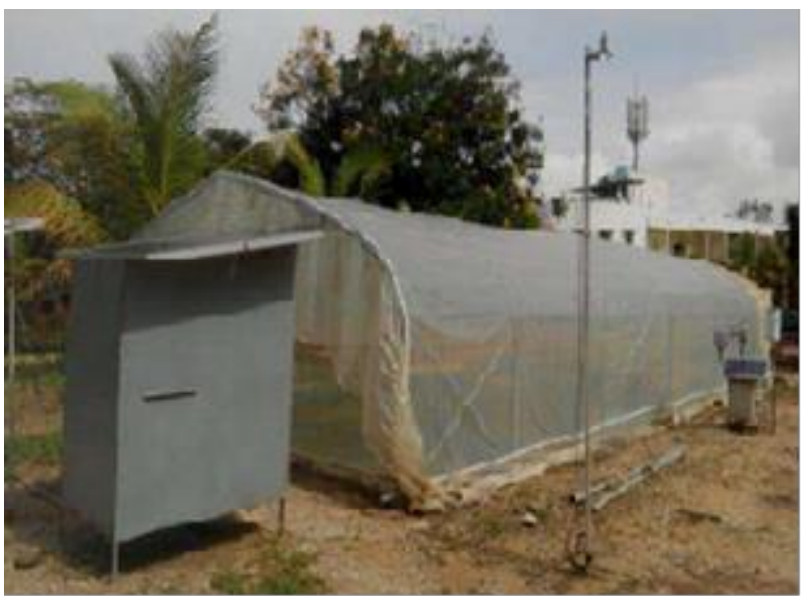

Fig. 1. Representative schema of the greenhouse at the Ecole Supérieure Polytechnique de Dakar

The principle is as follows: the sun's rays pass through the plastic film cover heating the air inside the greenhouse, as well as the low concrete floor. This keeps the heat trapped because the plastic film stops the radiation from being emitted to the outside. In such situations, the low floor absorbs most of the sun's rays [12].

\subsection{Methodology}

A "Log Tag" temperature and relative humidity recorder was used. This sensor is placed outdoors in a sheltered place from the sun at the end of recording the temperature and humidity of the outside air. The Log Tag recorder has a memory capacity of $2 \times 8000$ points for temperature and humidity with an accuracy of $\pm 1 \mathrm{~K}$ $\left(0{ }^{\circ} \mathrm{C} \ldots 50{ }^{\circ} \mathrm{C}\right)$ and $\pm 3 \% \mathrm{RH}\left(25^{\circ} \mathrm{C}, 20 \% \ldots 80 \%\right)$. Its measuring range is from -40 to $85{ }^{\circ} \mathrm{C}$ and from 0 to $100 \%$ relative humidity with a setting step of up to 30 seconds at several hours. Its resolution is $0.1 \% \mathrm{RH}$ and $0.1^{\circ} \mathrm{C}$. The recorder collected the temperature and humidity from the outside air throughout the day of November 13, 2018. These data were plotted in Figure 2 and were used as the initial condition of the outdoor air in the CFD simulation of our greenhouse. The soil has a low temperature variation at a certain depth due to its high thermal inertia. This soil temperature is a function of depth $\mathrm{z}$ from the parameters of the soil surface: the annual mean temperature at the soil surface, the amplitude of the temperature at the soil surface (delta ${ }^{\circ} \mathrm{C}$ ) and the phase constant of the soil surface temperature. These parameters are necessary to run the Energyplus program called Calcsoilsurftemp. The ground conditions around the system, the ground surface conditions and the weather file are the input data required to run the calcsoilsurftemp program. In Table 1 we have the data of the program that outputs the soil parameters. 
Table 1. soil parameters

\begin{tabular}{|c|c|c|}
\hline $\begin{array}{lr}\text { Annual } & \text { Average } \\
\text { Soil } & \text { Surface } \\
\text { Temperature }\left({ }^{\circ} \mathrm{C}\right)\end{array}$ & $\begin{array}{l}\text { Amplitude of Soil } \\
\text { Surface } \\
\text { Temperature }\end{array}$ & $\begin{array}{l}\text { Phase Constant of } \\
\text { Soil Surface } \\
\text { Temperature }\end{array}$ \\
\hline 25.479703903198 & 3.051382303238 & 16 \\
\hline
\end{tabular}

Heat transfers by conduction, convection, solar radiation and thermal radiation in a solar greenhouse are the results of heat and mass exchanges between the layers of the greenhouse [13]. It is assumed that the transfer is unidirectional between the absorber and the ground by conduction, as the latter plays the role of storing and releasing heat in the greenhouse.

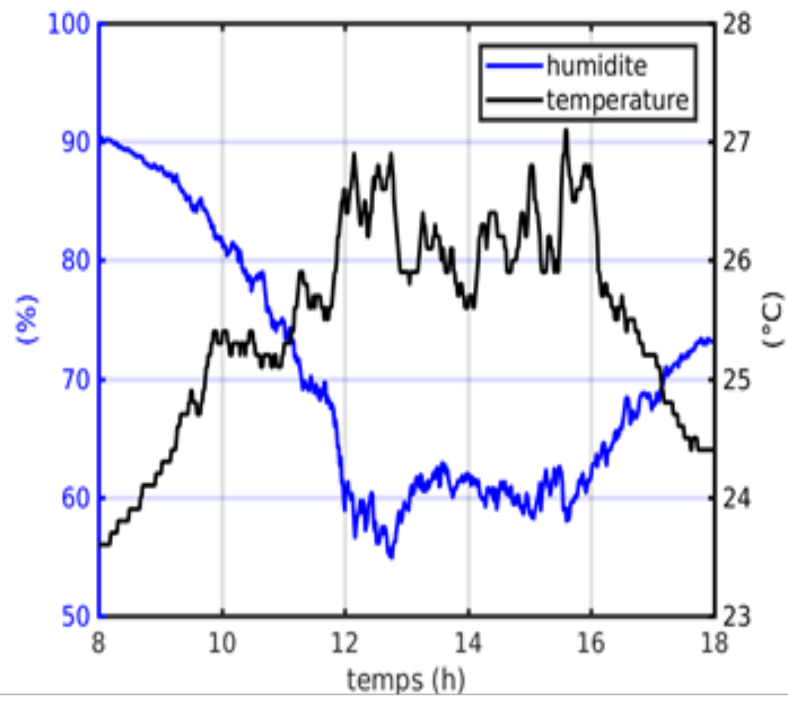

Fig.2. Outdoor climatic conditions of the temperature and humidity of the cloudy day of 13 November

\subsection{Numerical Model}

The Fluent CFD code available in version 17.0, allows to explicitly calculate the air flow field and temperature distribution in a greenhouse by solving the numerical transport equations. The 3-D conservation equation, describing the transport phenomenon for a stationary flow in free convection, is as follows:

$$
\frac{\partial w \phi)}{\partial z}+\frac{\partial v \phi)}{\partial y}+\frac{\partial w \phi)}{\partial z}=\Gamma \cdot \nabla^{2} \phi+S_{\phi}
$$

In equation (1), $\phi$ is the quantity of transport in the three conservation equations: mass, amount of motion (Navier-Stokes) and energy; $\mathrm{u}, \mathrm{v}$, and $\mathrm{w}$ are the components of the velocity vector; $\Gamma$ is the diffusion coefficient and $\mathrm{S}_{\phi}$ is the source term that can be cited (T. Bartzanas et al., 2004) [7] and other researchers [14, 15, $16]$.

To account for gravity effects, the Boussinesq hypothesis is imposed, which means that the buoyancy force due to the difference in air density is added as the source term in the equation of the quantity of motion [14]. The standard $\mathrm{k}-\varepsilon$ turbulence model is activated to model turbulent transport. This standard k- $\varepsilon$ model remains the standard in farm building modeling and applications. Nevertheless, some studies have suggested complex turbulence models compared to the standard $\mathrm{k}-\varepsilon$ model, which does not appear to make any significant comparisons between models [17]. The SIMPLEC method was used for the coupled pulse of pressure and velocity, and the second order for discretization schemes. The convergence criteria for residues are less than $10^{-6}$ for energy, $10^{-3}$ for continuity and $\mathrm{k}-\varepsilon$ equations. Table 2 is the characteristic of the physical property of the components of the greenhouse. The cover is a semi-transparent solid with a transmittance of 0.75 .

\subsection{Radiation model}

The Ordered Discrete Radiation (DO) model was used to discretize the Radiation Heat Transfer Equation (RTE) for a finite number of discrete solid angles, each associated with a vector direction fixed in the global Cartesian system, instead of adding additional heat sources [10]. The equation used in the DO model is:

$$
\begin{aligned}
& \nabla \cdot\left(I(\vec{r}, \vec{s}) \vec{s}+\left(a+\sigma_{s}\right) I\left(\vec{r}_{,}, \vec{s}\right)=a n^{2} \frac{\sigma T^{4}}{\pi}+\right. \\
& \frac{\sigma_{s}}{4 \pi} \int_{0}^{4 \pi} I\left(\vec{r}_{,}, \vec{s}^{\prime}\right) \Phi\left(\vec{r}_{s}, \vec{s}^{\prime}\right) d \Omega^{\prime}
\end{aligned}
$$

Where $\sigma_{\mathrm{s}}$ is scattering coefficient; $\sigma$ is the StefanBoltzmann constant; $\mathrm{I}$ is radiation intensity $\left(\mathrm{W} . \mathrm{m}^{-2}\right)$; $\mathrm{T}$ is temperature $\left({ }^{\circ} \mathrm{C}\right)$; $\Phi$ is phase function; $\Omega$ ' is solid angle.

Table 2. Physical properties of greenhouse materials

\begin{tabular}{|l|l|l|l|l|l|l|l|}
\hline & $\rho$ & $\mathrm{C}_{\mathrm{p}}$ & $\lambda$ & $\alpha$ & $\begin{array}{l}\text { Scat } \\
\text { coef }\end{array}$ & $\mathrm{n}$ & $\varepsilon$ \\
\hline $\mathrm{PE}$ & 921 & 2300 & 0,34 & 0,04 & 0 & 1 & 0,79 \\
\hline Air & 1,22 & 1006 & 0,024 & - & 0 & 1 & - \\
\hline Concrete & 2300 & 879 & 1,75 & 0,6 & 1 & 1 & 1 \\
\hline
\end{tabular}

\subsection{Meshing and boundary conditions}

For the mesh size the tetrahedral coordinates are used for the internal volume domain of the greenhouse. Fine resolutions are imposed in the vicinity of the low floor, roof and walls because thermal granules are important in these levels. The three-dimensional domain was divided into 119202 elements and 256967 knots, illustrated in 
(fig 3). The ground temperature is assumed to be constant and is an initial condition, as specified in Table 1. The polyethylene film cover of the greenhouse is in the same condition as the outside air temperature equal to $300.25 \mathrm{~K}$ taken at $15 \mathrm{~h} 36 \mathrm{mn}$, which corresponds to the large peak of our measurement (fig. 2) with a convective coefficient fixed at $25 \mathrm{w} / \mathrm{m}^{2} \mathrm{k}$.

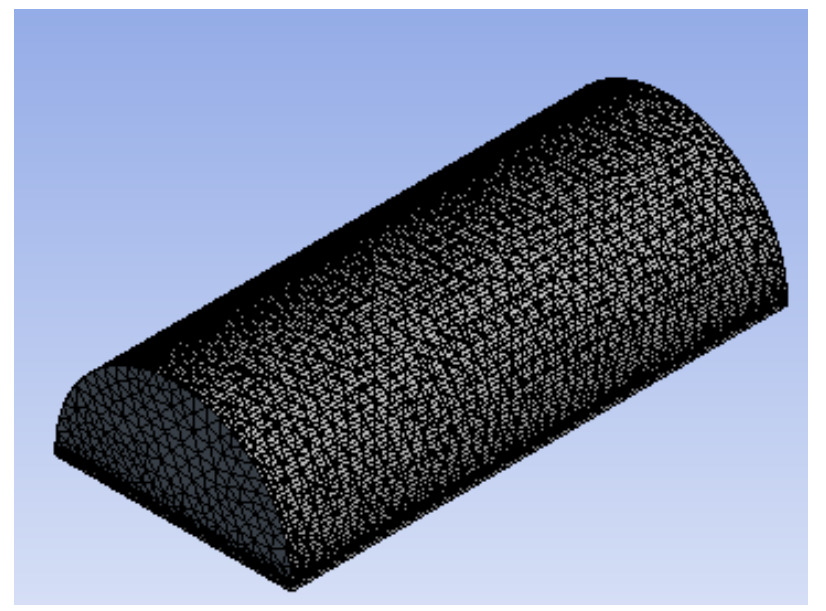

Fig.2. Mesh size of the calculation domain

\section{Results and Discussion}

\subsection{Temperature distribution inside the greenhouse}

The temperature distribution in the center of the greenhouse for the day of 13 November 2018 is shown in Figure 3. This simulation is carried out at $15 \mathrm{~h} 36 \mathrm{mn}$ with a practically cloudy sky.

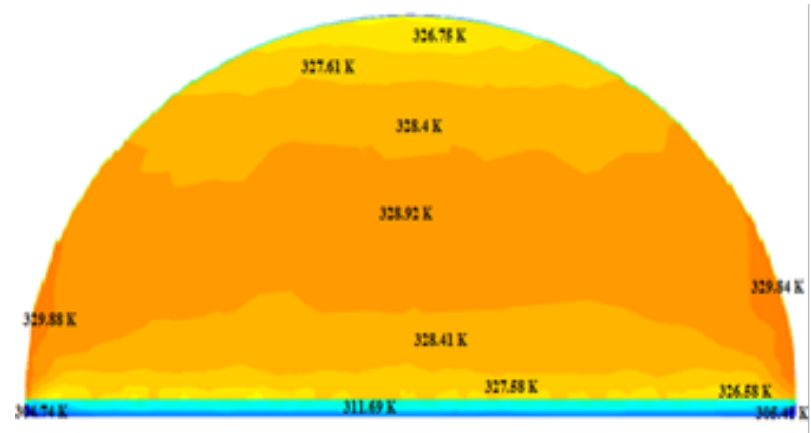

Fig. 3. Temperature distribution in the center of the greenhouse for a simulation during the day at $15 \mathrm{~h} 36 \mathrm{mn}$

The distribution of the air temperature in the greenhouse increases by $276.95 \mathrm{~K}$ compared to the average at the sides. This distribution of the temperature inside the greenhouse is achieved by the transfer of heat between the outside air and the greenhouse cover. When the outside temperature increases, we have an increase in the air temperature of the greenhouse due to the convection between the plastic film and the greenhouse air. Due to the low air velocities, the greenhouse air temperature reaches high values. At ground level, deep-seated temperatures are lower than those on ground surfaces. This is because the solar radiation in the greenhouse is absorbed by the upper surface of the ground, which allows it to store a large amount of energy. It is also noted that ground temperatures in the greenhouse are higher in the center than on the sides due to heat transfers from the outside of the greenhouse.

\subsection{Air velocity distribution inside the greenhouse}

In Figure 4, we will present the distribution of the velocity field in the greenhouse for November 13, 2018.

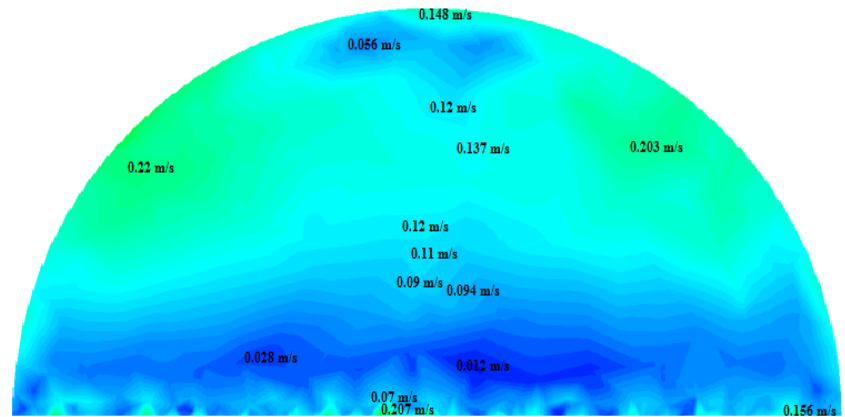

Fig. 4. Speed distribution in the center of the greenhouse for a simulation during the day at $15 \mathrm{~h} 36 \mathrm{mn}$

The movement of the air is characterized by a vertical profile in the center of the greenhouse. Air velocity is higher along the plastic film and in the center of the greenhouse where air temperatures are important. However, between low floor and the center air velocities are weak. The cold air heats up by convection along the roof and floor. Figure 5 shows velocity vectors in a longitudinal plane. We observe the creation of two eddies on either side of the central current. There is a strong draught near the roof and with a circular loop in the center that mixes the air in the greenhouse.

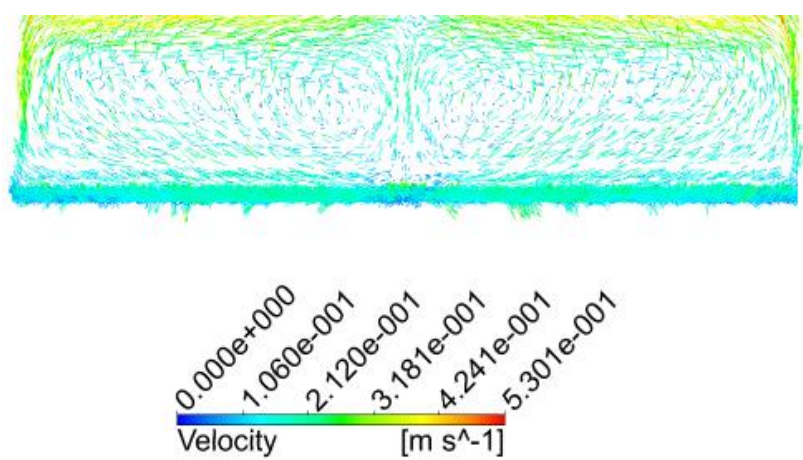

Fig.5. Velocity vectors in the greenhouse on a longitudinal plane.

\section{Conclusions}

The distribution of air velocities and temperatures generated by buoyancy forces in a greenhouse used as a dryer were digitally analyzed using CFD software. The boundary conditions of the model take into account the temperature of the outside air, solar radiation through the "Solar Load Model" with the resolution of the radiation transfer equations (RTE) by the discrete ordered method 
DO. The model also took into account the nature of the soil with the Energyplus program called Calcsoilsurftemp. For a closed greenhouse subject to climatic conditions, air movement is characterized by convection along the roof and low floor. This air movement is characterized by low air velocities between the low floor and the center and slightly higher velocities in the center. We found also higher air velocities along the roof with an average of $0.114 \mathrm{~m} / \mathrm{s}$. This study also shows a good distribution of temperatures which remain homogeneous with an average of $325.95 \mathrm{~K}$ while the temperature of the outside air is equal to $300.25 \mathrm{~K}$. The results obtained in this work have made it possible to frame our future work to evaluate a transitional model and optimize the operation of the dryer.

\section{KEYWORDS}

Solar dryer, CFD simulation, DO, temperature and air velocity field.

The acknowledgements:

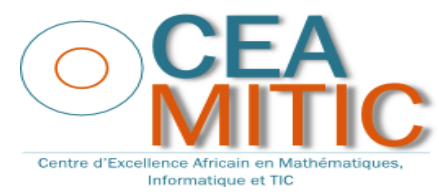

Centre d'Excellence Africain en Mathématiques, Informatique et Tic (CEA-MITIC)

\section{References}

1. J. Kaewkiew, S. Nabnean and S. Janjai, Experimental investigation of the performance of a large-scale greenhouse type solar dryer for drying chilli in Thailand, Procedia Engineering 32 (2012) 433 - 439.

2. E. Mashonjowa, F. Ronsse, J. R. Milford and J. G. Pierters, Modelling the thermal performance of a naturally ventilated greenhouse in Zimbabwe using a dynamic greenhouse climate model, Solar Energy 91 (2013) 381-393.

3. O. Prakash and A. Kumar, Solar greenhouse drying: A review, Renewable and Sustainable Energy Reviews 29 (2014) 905-910.

4. J. Dilip, Modeling the performance of greenhouse with packed bed thermal storage on crop drying application, Journal of Food Engineering 71 (2005) 170178.

5. V. P. Sethi and S. Arora, Improvement in greenhouse solar drying using inclined north wall reflection, Solar Energy 83 (2009) 1472-1484.

6. K. Jitjack, S. Thepa, K. Sudaprasert and P. Namprakai, Improvement of a Rubber Drying Greenhouse with a parabolic cover and enhanced panels, Energy and Buildings, (2016) vol. 6581.

7. T. Bartzanas, T. Boulard and C. Kittas, Effect of Vent Arrangement on Windward Ventilation of a Tunnel Greenhouse, Biosystems Engineering (2004) 88 (4), 479-490.
8. P. E. Bournet, S. A. Ould Khaoua and T. Boulard, Numerical prediction of the effect of vent arrangements on the ventilation and energy transfer in a multi-span glasshouse using a bi-band radiation model, Biosystems Engineering 98 (2007) 224- 234.

9. Davide Piscia, Juan I. Montero, Esteban Baeza and Bernard J. Bailey, A CFD greenhouse night-time condensation model, Biosystems Engineering 111 (2012) 141-154.

10.Xiangli He, Jian. Wang, Shirong. Guo, Jian. Zhang, Bin. Wei, Jin. Sun and sheng. Shu, Ventilation optimization of solar greenhouse with removable back walls based on CFD, Computers and Electronics in Agriculture (2018) vol. 149, pp. 16-25.

11. G. Tong, D. M. Christopher and B. Li, Numerical modelling of temperature variations in a Chinese solar greenhouse, Computers and Electronics in Agriculture 68 (2009) 129-139.

12. T. Boulard, R. Haxaire, M. A. Lamrani, J. C. Roy and A. Jaffrin, Characterization and Modelling of the Air Fluxes induced by Natural Ventilation in a Greenhouse, J. agric. Engng Res. (1999) 74, 135-144.

13. E. Mashonjowa, F. Ronsse, J.R. Milford and J.G. Pieters, Modelling the thermal performance of a naturally ventilated greenhouse in Zimbabwe using a dynamic greenhouse climate model, Solar Energy 91 (2013) 381-393.

14. T. Boulard and S. Wang, Experimental and numerical studies on the heterogeneity of crop transpiration in a plastic tunnel, Computers and Electronics in Agriculture 34 (2002) 173-190.

15. H. Majdoubi, T. Boulard, H. Fatnassi and L. Bouirden, Airflow and microclimate patterns in a onehectare Canary type greenhouse: An experimental and CFD assisted study, Agricultural and Forest Meteorology 149 (2009) 1050-1062.

16. Keesung Kim, Jeong-Yeol Yoon, Hyuck-Jin Kwon, Jin-Hee Han, Jung Eek Son, Sang-Woon Nam, Gene A. Giacomelli and In-Bok Lee, 3-D CFD analysis of relative humidity distribution in greenhouse with a fog cooling system and refrigerative dehumidifiers, Biosystems Engineering 100 (2008) 245- 255.

17. Tomàs Norton, Da-Wen Sun, Jim Grant, Richard Fallon and Vincent Dodd, Applications of computational fluid dynamics (CFD) in the modelling and design of ventilation systems in the agricultural industry: A review, Bioresource Technology 98 (2007) 2386-2414.

18. O. Prakash and A. Kumar, Solar greenhouse drying: A review, Renewable and Sustainable Energy Reviews 29 (2014) 905-910.

19. T. Bartzanas, T. Boulard and C. Kittas, Effect of Vent Arrangement on Windward Ventilation of a Tunnel Greenhouse, Biosystems Engineering (2004) 88 (4), 479-490. 